\title{
Effects of Phoenix dactylifera Syrup Consumption on the Severity of Labor Pain and Length of the Active Phase of Labor in Nulliparous Women
}

\author{
Leila Fathi ${ }^{1}, *$ Kourosh Amraei ${ }^{2}$
}

\begin{abstract}
Background \& Aims: Delivery is a painful event, and the management of labor pain is of utmost importance. The present study aimed to assess the effects of the oral consumption of date palm (Phoenix dactylifera) syrup on labor pain and length of the active phase of labor in nulliparous women.

Materials \& Methods: This randomized clinical trial was conducted on 64 healthy volunteer nulliparous women who met the inclusion criteria at Asali Teaching Hospital in Khorramabad, Iran. The participants were selected randomly and assigned to two groups of intervention (date palm syrup) and control (32 subjects per group). Data were collected using a questionnaire with the domains of demographic characteristics and vaginal examinations in labor, and pain intensity was assessed using the visual analogue scale (VAS). Pain intensity was measured every 30 minutes during the active phase of labor. Data analysis was performed in SPSS version 16.

Results: The mean score of pain intensity was significantly lower in the intervention group compared to the control group $(\mathrm{P}<0.05)$. Moreover, the mean length of the active phase of labor was significantly lower in the intervention group compared to the control group $(\mathrm{P}<0.01)$.

Conclusion: According to the results, the consumption of date palm syrup significantly decreased pain intensity and the length of delivery, so that despite reducing the labor pain, labor was not prolonged, and the length of the active phase of labor significantly reduced as well. Considering the importance of evidence-based research and its use in practice, further investigations in this regard are required.
\end{abstract}

Keywords: Phoenix dactylifera, Labor Pain, Active Phase of Labor

\section{Conflict of Interest: No}

How to Cite: Fathi L, Amraei K. Effects of Phoenix dactylifera Syrup Consumption on the Severity of Labor Pain and Length of the Active Phase of Labor in Nulliparous Wome. Iran Journal of Nursing. 2019; 31(116):18-27.

Received: 10 Nov 2018

Accepted: 7 Feb 2019

1. Lecturer, Department of Midwifery, School of Nursing and midwifery, Lorestan University of Medical Sciences, Khorramabad, Departement of Midwifery, School of Nursing and midwifery, Tehran University of medical Science, Tehran, Iran

2. Assistant Professor, Departement of Psychology, Faculty of Literature and Humanities, Lorestam University, Khorramabad, Iran. (*Correspnding author) Tel: $06633120001 \quad$ Email: amraei.k@lu.ac.ir 


\title{
تأثير مصرف شربت خر ما بر شدت درد زايمان و طول فاز فعال زايمان زنان نخستزا
}

\author{
ليلا فتحى '، *:كورش امرايى
}

جكيده

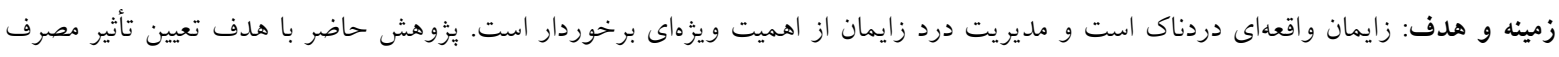

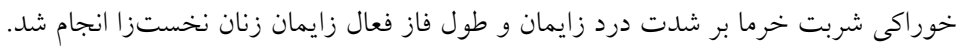

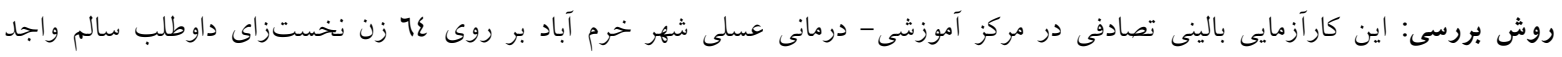

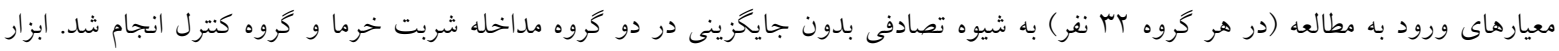

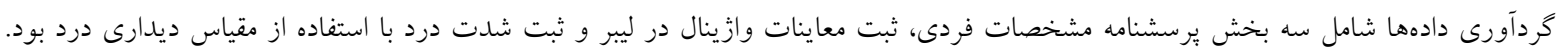

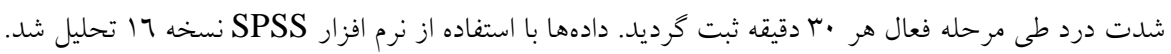

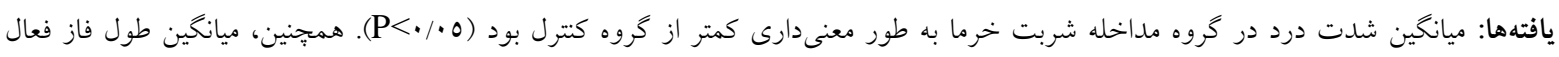

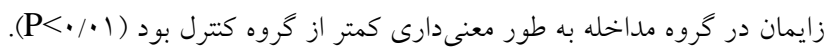

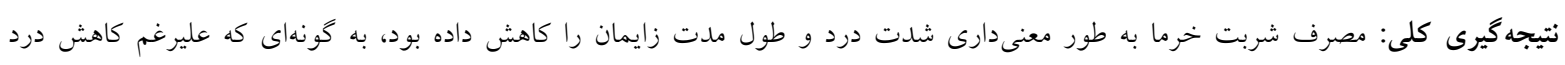

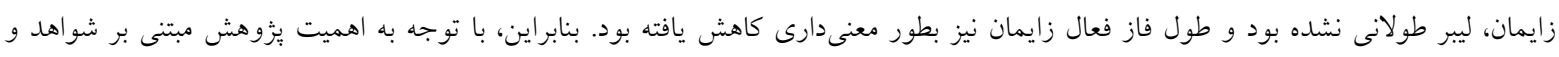

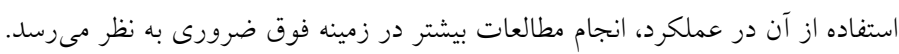

كليد وازهها: خرما، درد زايمان، فاز فعال زايمان

$$
\text { تاريخ داريخ منافع: ندارد }
$$

\footnotetext{
ا. مربى، تروه مامايى، دانشكده برستارى و مامايى، دانشكاه علوم يزشكى لرستان، خرم آباد، تروه مامايى، دانشكده برستارى و مامايى، دانشكاه علوم

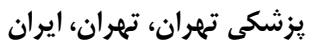

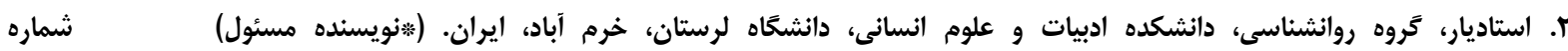


از اهميت ويزهاى برخوردار است(·). حتى مديريت مقدمه

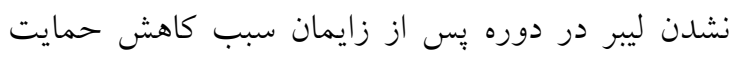

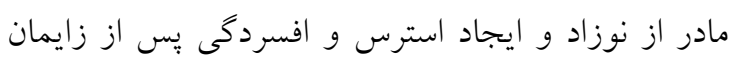

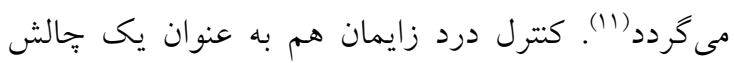

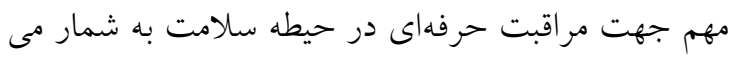

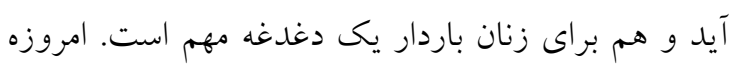
به منظور كاهش درد و خوشايندسازى فرآيند زايمانى از

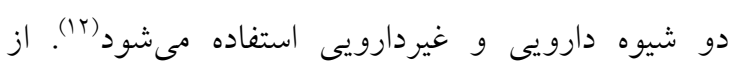
روشهاى دارويى كاهش درد مىتوان به استفاده از

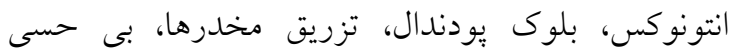
اييدورال، بى حسى نخاعى و بى هوشى اثاره نمود (rا').

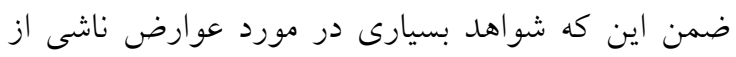
استفاده آنها وجود دارد مىتوان به طولانى شدن مرحله اول و دوم ليبر، افت فشار خون، كاهش سرعت نزول جنين و برادى كاردى جنينى اشاره كردو(ع). بنابراين

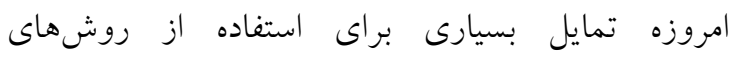

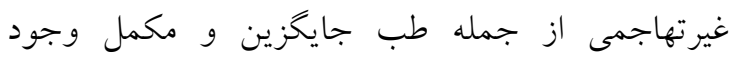

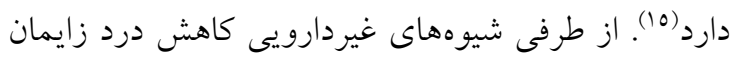
سبب ايجاد احساس رضايت و خودكنترلى بيشتر مادر و و

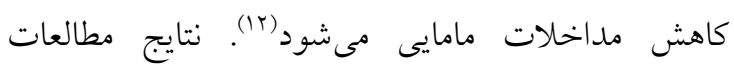

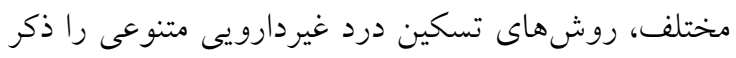
مىكنند. از جمله روشهاى خوشايند سازى و تسكين

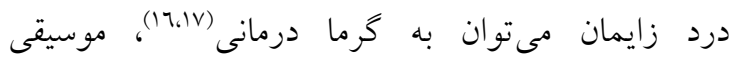
درمانى، رايحه درمانى، رفلكسولوزى، تن آرامى و تكنيك دوان به

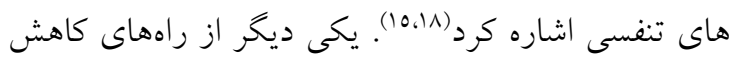
درد مصرف مايعات حاوى مواد مغذى است كه ممكن است تأثيراتى بر روى درد و راحتى فرد داشته باشد (19).

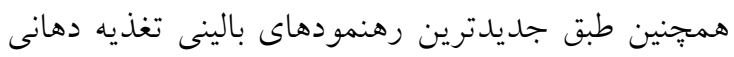
زنان باردار كه توسط كالج يرستارى و مامايى آمريكا ارائه شد، محدود كردن دريافت مواد غذايى طى ليبر موجب

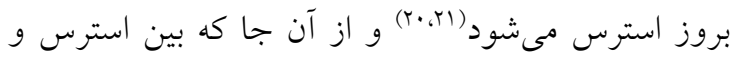

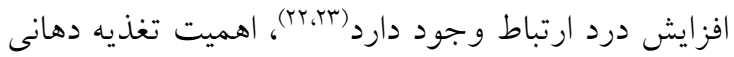
حين فرآيند ليبر بيشتر مشخص مىشود. در همين راستا

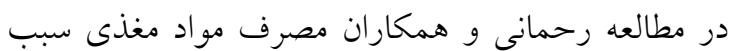
انجمن بين المللى مطالعه درد (IASP) در تعريف درد جنين مى گويد: درد يك تجربه حسى و عاطفى ناخوشايند

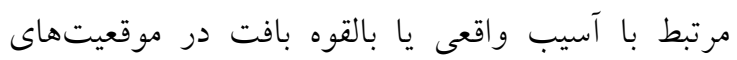

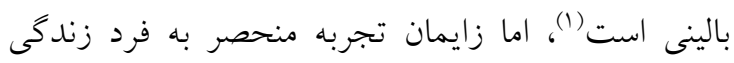

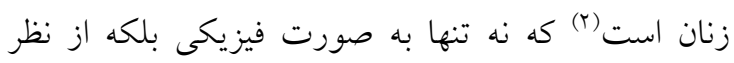

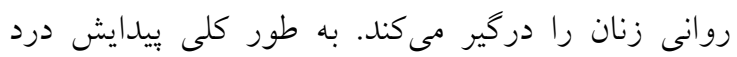
زايمان ناشى از بيمارى نيست بلكه بِديدهاى فيزيولوزيك

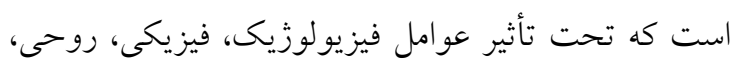

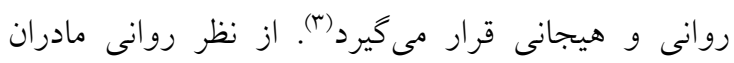

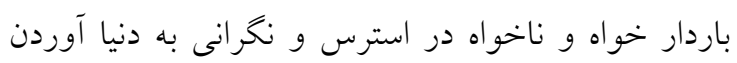

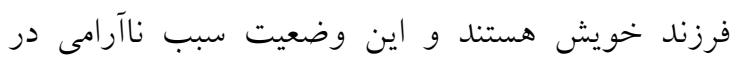

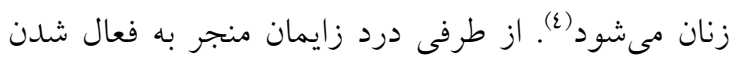

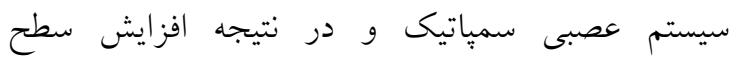
و Norepinephrine Catecholamines كنترل نشدن درد زايمان، افزايش بيش از بيش اين مواد همراه با انقباض عروقى ناشى از كاتكول آمينها زمينه كاهش جريان خون رحمى را فراهم ساخته و به دنبال آن

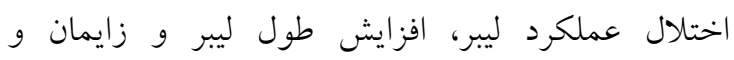

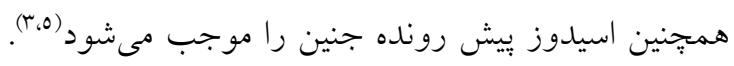

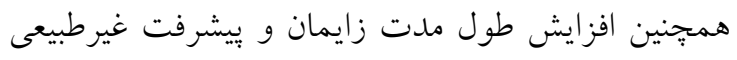

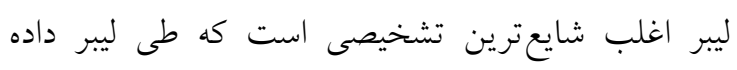

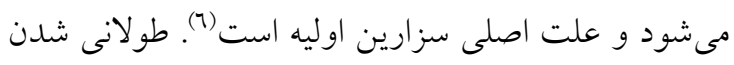

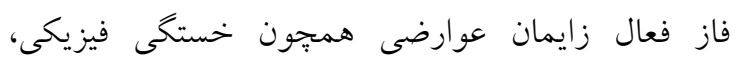

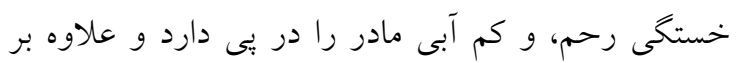

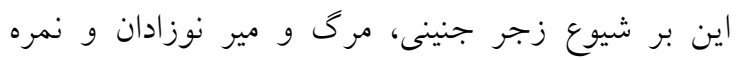

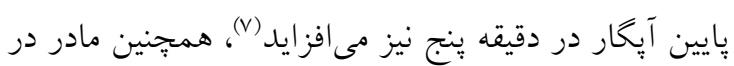
معرض خطر بيشتر خونريزى و عفونت پِ از زايمان، و و

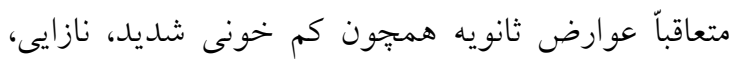

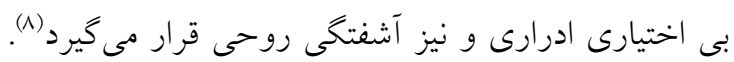

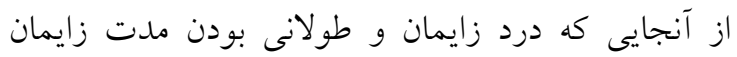

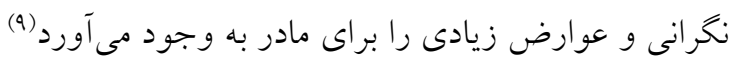
به همين سبب است كه روشهاى خوشايند سازى زايمان 
صورت كارآزمايى بالينى تصادفى انجام يذيرفت. طى آن

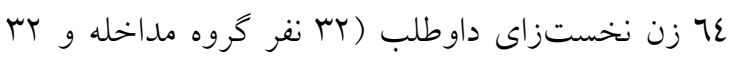

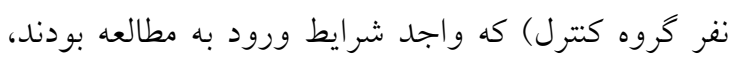
״ِ از شرح كامل اهداف يُزوهش، كسب رضايت شركت

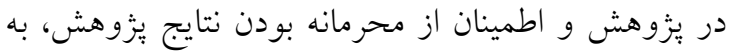

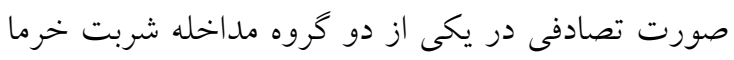
و كروه كنترل قرار كرفتند. معيارهاى ورود به مطالعه

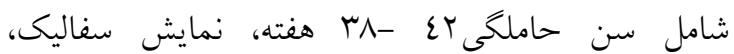
سلامت جسمى و روانى، نداشتن سابقه نابارورى، داشتن

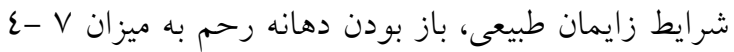
سانتى متر و نداشتن سابقه حساسيت به خرما بود. لازم به

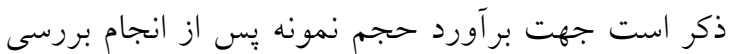
هاى اوليه و مطالعه متون يزوهش مرتبط با مداخلات (19)،

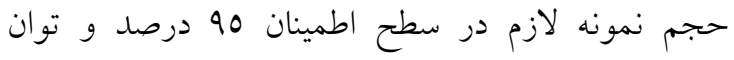

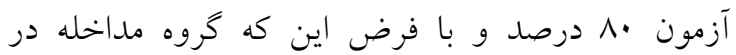
مقايسه با كروه كنترل مىتواند شدت درد را به ميزان d=1/V0 فرمول كوكران، بr نفر در هر گرووه در نظر گرفته شد.

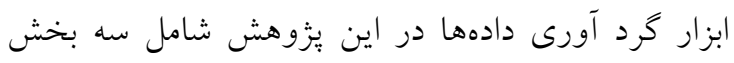

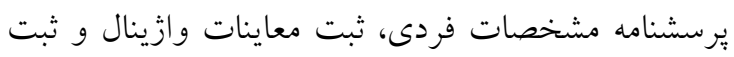

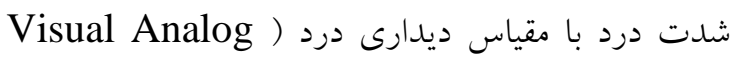
Scale: VAS مترى بود. اين ابزار، مقياسى استاندارد بوده و در يُزوهش هاى مختلف جهت سنجش درد زايمان استفاده شده است و روايى و بايايى مناسب آن در مقياس جهانى ثابت شده (r. (r) در فرآيند يزّوهش، يُزوهشخر كنترل و ثبت تمامى معاينات را شخصاً در دو كروه مداخله و كتترل انجام داد. بدين ترتيب كه طول و فواصل انقباضات رحم و تعداد ضربان قلب جنين در بلدو ورود به مطالعه و سبس هر •r دقيقه و ديلاتاسيون، افاسمان، جايخاه و وضعيت كيسه آب در بدو ورود به مطالعه و سبس هر دو ساعت با انجام

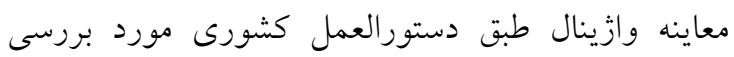
قرار كرفت و طول مدت فاز فعال زايمان بر حسب دقيقه
كاهش طول مرحله دوم زايمان شده بود(Y)، و نيز در

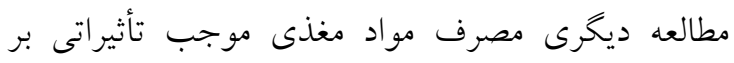

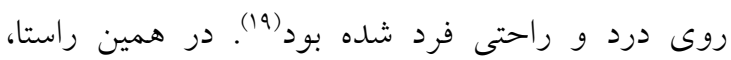
جديدترين يُوهش خابٍ شده در مجله يرستارى آمريكا دريافت مواد غذايى طى ليبر را عاملى براى رضايتمندى لئل

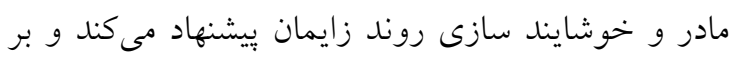

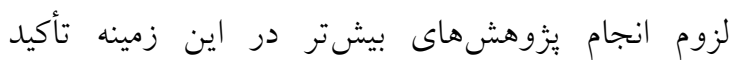

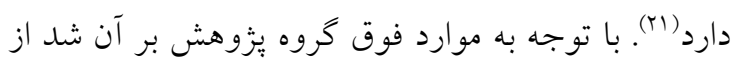
خرما كه ميوه بومى و صادراتى كشورمان است و از برن ديدكاه طب سنتى ايرانى همواره مورد توجه بوده است در يُزوهش خود استفاده كند. لازم به ذكر است در آيات דr-Y سوره مريم نيز به حضرت مريم هنگام تولد

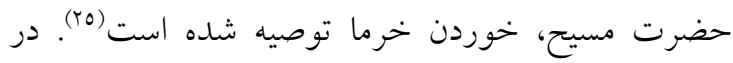
مطالعات صورت كرفته در خصوص استفاده از خرما در

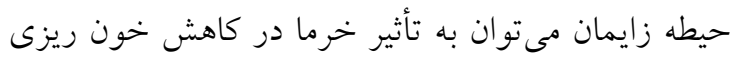

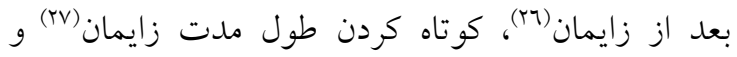

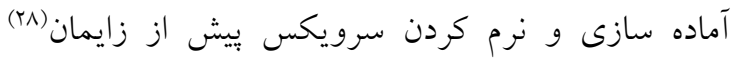
اشاره كرد. با اين وجود طى جست و و جوى وسيع رايانه

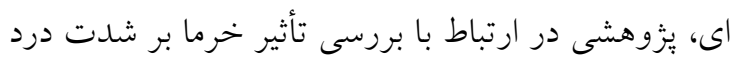

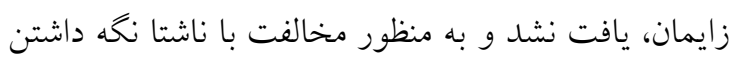
مادر، تنها در مطالعه رحمانى تثير دريافت مواد غذايى بـاني

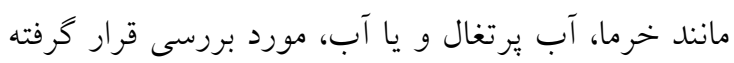
بود با توجه به كافى نبودن يزوهشهاى انجام شده، هدف از يُزوهش حاضر نشان دادن اثربخشى شربت خرما در كاهش درد و طول فاز فعال زايمان در زنان نخستزا تران

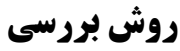

يزّوهش حاضر حاصل طرح تحقيقاتى مشترى دانشگاه

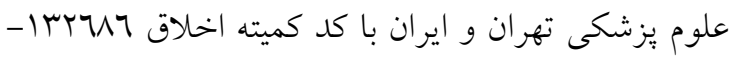
q q.r.r كار آزمايى بالينى 16N كه در مركز آموزشى درمانى عسلى شهر خرم آباد به به 


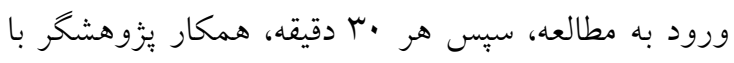

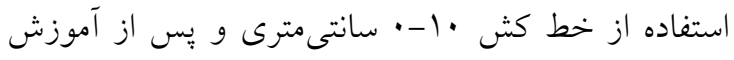

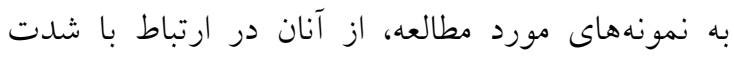

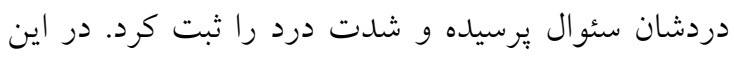

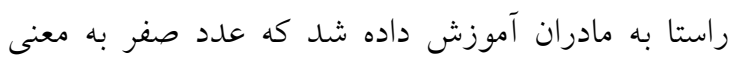
نداشتن درد است و با افزايش عدد انتخابى شدت درد بيشتر مىشود، به كونهاى كه عدد ·ل نشانكر بالاترين شدت درد است. جهت تجزيه و تحليل دادهها، از نرم افزار SPSS نسخه 17 استفاده شد.

\section{بافتهها}

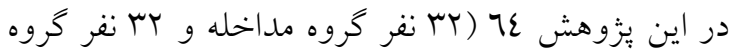
كترل) زن نخستزاى واجد شرايط وارد مطالعه شدند كه از نظر مشخصات جمعيت شناختى در بدو ورود به

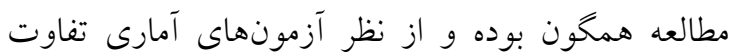
معنى دارى نداشتند (جدول شماره ()).
ثبت شد. يُزوهشكر در تمامى طول ليبر تا زمان زايمان،

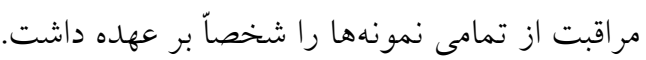

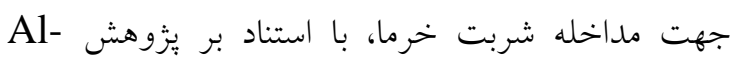
Kuran پِ از استخراج هسته در مخلوط كن كاملا مخلوط شد و سبس جهت اطمينان از صافى رد گرديد و به صورت كاملا صاف شده و بدون تفاله به صورت شربتى مخلوط در •10 ميلى ليتر آب تهيه شد. در كروه كنترل نيز هيج

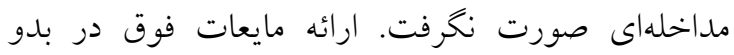
ورود به مطالعه و سبس در صورت تمايل هر •ج" ·"r دقيقه يك بار توسط خود يزوهشكر انجام شد و حجم مايعات دريافتى با ذكر زمان دريافت، ثبت گرديد. در كروه كنترل نيز صرفاً در صورت تمايل آب ساده داده و ثبت شد. جهت بيش گيرى از تورش در طول يزوهش، صرفا ثبت

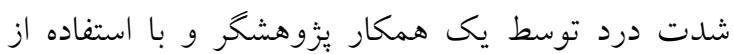
خط كش درد، صورت كرفت. بدين صورت كه در بدو

جدول شماره (: مشخصات توصيفى و شاخص هاى آمارى متغيرهاى جمعيت شناختى

\begin{tabular}{|c|c|c|c|c|c|}
\hline$P$ value & df & 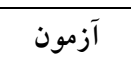 & 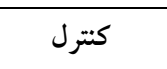 & شربت خرما & متغير \\
\hline.$/ 9 V$ & $\pi$ & $\mathrm{T}=-\cdot / \cdot \varepsilon$ & $r \varepsilon / \cdot V(r / q 1)$ & $r \varepsilon / \cdot \Gamma(r / \mu l)$ & سن (سال) M(SD) \\
\hline$\cdot / 9$ & $\pi$ & $\mathrm{T}=\cdot / \mathrm{T}$ & $\mathrm{rq} / \mathrm{OV}(1 / \cdot)$ & $r q / \mu r(\cdot / 9 \Lambda)$ & سن باردارى (هفته) M(SD) \\
\hline \multirow[t]{3}{*}{$\cdot / 17$} & 1 & $\mathrm{X}^{2}=\cdot / \mathrm{\Lambda} \Lambda$ & $r \cdot / r(1 r)$ & $I V / T(1 I)$ & سطح تحصيلات: زيردييلم \\
\hline & & & $r \cdot / r(\mid r)$ & $r \mid / 9(1 \varepsilon)$ & دييلم \\
\hline & & & $9 / 2(7)$ & $1 \cdot / 9(\mathrm{~V})$ & دانشخاهى \\
\hline \multirow[t]{2}{*}{$\cdot / / q$} & 1 & $\mathrm{X}^{2}=\cdot / \mathrm{Nr}^{\mathrm{N}}$ & $\wedge \varepsilon r(\Upsilon \wedge)$ & $\varepsilon \nabla / q\left(\Gamma_{\bullet}\right)$ & وضعيت اشتغال: خانهدار \\
\hline & & & $\tau / Y(\varepsilon)$ & $r / l(r)$ & 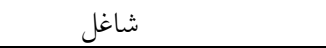 \\
\hline \multirow[t]{2}{*}{$\cdot / 999$} & 1 & & $\varepsilon \Lambda / \varepsilon(\mu))$ & $\varepsilon \Lambda / \varepsilon\left(\Gamma_{1}\right)$ & وضعيت باردارى: خواسته \\
\hline & & & $1 / 7(1)$ & $1 / 7(1)$ & ن اخخو استه \\
\hline
\end{tabular}

نشان داد كه ميانخين نمره درد كسب شده در هر دو گروه مورد مطالعه در بدو ورود تفاوت معنىدارى نداشت و هر دو گروه از نظر شدت درد در بدو ورود به مطالعه در يك ليك

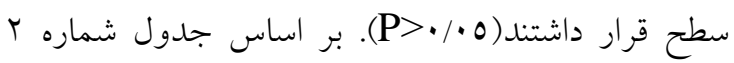
مطابق با نتايج آزمون تى مستقل در ارتباط با شدت درد

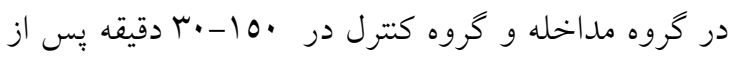
ورود به مطالعه حاكى از آن بود كه شدت درد يس از
در راستاى ياسخدهى به فرضيات يزوهش، با توجه به اندازهيرى شدت درد در زمانهاى مختلف و داشتن دو كروه از آزمون تى مستقل استفاده شد. قابل ذكر است كه همسان نبودن درد در كروه شربت خرما و كنترل در بدو ورود به مطالعه مىتوانست به عنوان يك متغير مداخلهكر تفسير نتايج را تحت تأثير قرار دهد. بنابراين تعيين شدت درد قبل از مداخله انجام شد. نتيجه آزمون تى مستقل 


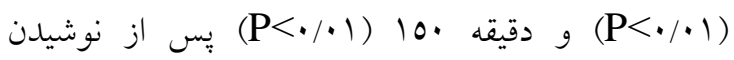

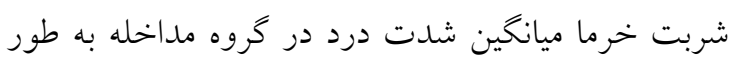
معنى دارى كاهش يافته بود (جدول شمارهب). بنابراين،

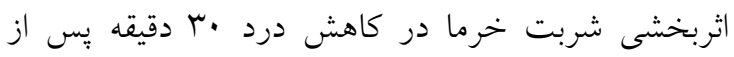

$$
\text { شروع مداخله بود. }
$$

كذشت •r دقيقه از مداخله در گروه مصرف كننده شربت

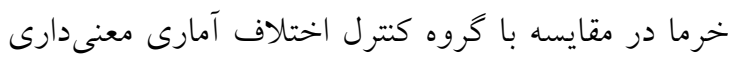

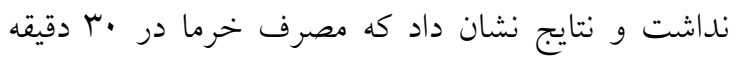
اول يُزوهش درد را كاهش نداده بود ولى در زمانهاى

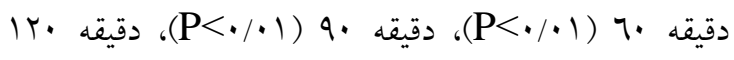

جدول شماره

\begin{tabular}{|c|c|c|c|c|c|}
\hline P-value & df & $\mathbf{t}$ & $\begin{array}{c}\text { كنتر } \\
\text { M (SD) }\end{array}$ & $\begin{array}{l}\text { شربت خرما } \\
\text { M (SD) }\end{array}$ & زمان سنجش \\
\hline$\cdot / 7 r 7$ & $7 T$ & $-\cdot / 29$ & $N / 1 \wedge(1 / 9 \cdot)$ & $V / 9 T(T / 1 T)$ & بدو ورود به مطالعه \\
\hline$\cdot / T \varepsilon$ & $\pi$ & $-1 / 0749$ & N/TO (I/NV) & $V / T r(1 / \varepsilon \cdot)$ & •r دقيقه ِّ از مداخله \\
\hline$\cdot / \cdot 1$ & $7 r$ & $-\varepsilon / \varepsilon q$ & $9 / 1 r(1 / .9)$ & $V / 09(1 / 01)$ & •ج دقيقه پِ از مداخله \\
\hline$\cdot / \cdot 1$ & $7 T$ & $-r / I r$ & $9 / r \circ(r / \cdot 7)$ & $V / 9 T(1 / V \cdot)$ & •9 دقيقه بِس از مداخله \\
\hline$\cdot / \cdot \cdot$ & rq & $-7 / 9 T$ & $9 / \cdot \vee(\cdot / 0 r)$ & $T / V \cdot(\cdot / 90)$ & •rا ادقيقه بِ از مداخله \\
\hline.$/ \cdot 1$ & 19 & $-\varepsilon / 7 \varepsilon$ & $O / N I(\cdot / \varepsilon 1)$ & $\cdot / \mathrm{V} \cdot(\cdot / 0 \mathrm{~V})$ & •ما دقيقه پِس از مداخله \\
\hline
\end{tabular}

به عنوان يك متغير مداخلهكر تفسير نتايج را تحت تأثير قرار دهد بنابراين ثبت ميزان ديلاتاسيون در بدو ورود به فيه

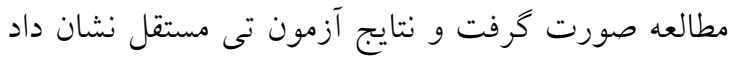
كه ميانخين ديلاتاسيون در بدو ورود به مطالعه در دو

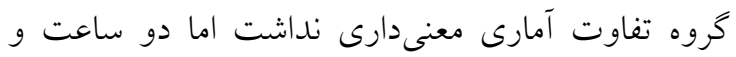
جهار ساعت يس از مداخله ميزان ديلاتاسيون دهانه رحم در كروه شربت خرما به طور معنىدارى بيشتر از خروه

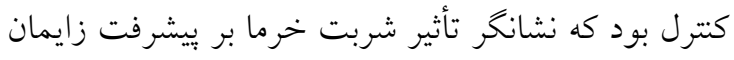
است (جدول شماره ب).
در اين يزوهش، جهت نشان دادن اثربخشى مصرف خوراكى خرما بر كاهش طول فاز فعال زايمان، ثبت

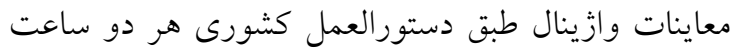
يك بار انجام شد (جدول شماره r) و در همين راستا طول فاز فعال زايمان از زمان ورود به مطالعه تا بان

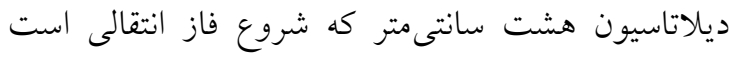

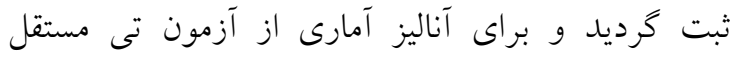

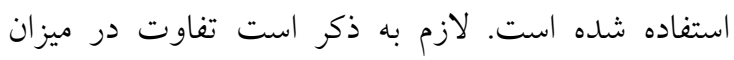
ديلاتاسيون دهانه رحم در بدو ورود به مطالعه ممكن بود بله

جدول شماره": مشخصات توصيفى معاينات وازينال و مقايسه دو تَروه

\begin{tabular}{|c|c|c|c|c|c|}
\hline$P$ value & df & $\mathbf{t}$ & كنترل & شربت خرما & 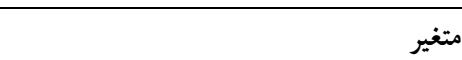 \\
\hline$\cdot / \mathrm{V} 7$ & $7 r$ & $-\cdot / \mu \cdot$ & $\varepsilon / 97(\cdot / 17)$ & $\varepsilon / q \cdot(\cdot / \mathrm{VV})$ & ديلاتاسيون بدو ورود (سانتيمتر) \\
\hline$\cdot / \cdots 1$ & Tr & $\varepsilon / \uparrow \cdot$ & $V / \cdot r(\cdot / q V)$ & $\operatorname{V} / \wedge \varepsilon(\cdot / 01)$ & ديلاتاسيون Y ساعت بعد مداخله (سانتيمتر) \\
\hline.$\cdots 1$ & $\varepsilon \varepsilon$ & $0 / 90$ & $\Lambda / r_{0}(\cdot / \mathrm{VI})$ & $9 / 7 \cdot(\cdot / V r)$ & ديلاتاسيون ع ساعت بعد مداخله (سانتيمتر) \\
\hline
\end{tabular}

دارى (P</ (P< ) كاهش بيدا كرده بود كه اين امر حاكى از تأثير مصرف خوراكى خرما در كاهش فاز فعال زايمان

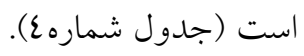

هم:جنين، نتايج حاكى از آن است كه طول فاز فعال زايمان

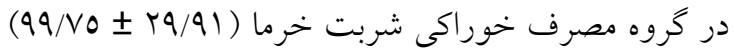

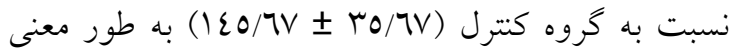

\begin{tabular}{|c|c|c|c|c|}
\hline P-value & df & $\bar{t}$ & طول فاز فعال زايمان & كرووههاى برُوهش \\
\hline & $\pi$ & $-T / Y r$ & $\begin{array}{l}99 / \mathrm{VO}(\mathrm{TQ/91)}) \\
120 / 0 \cdot(\mathrm{rO} / \mathrm{V})\end{array}$ & كروره كترل خوف خوراكى شربت خرما \\
\hline
\end{tabular}
جدول شمارهع: مشخصات توصيفى و آزمون t مستقل براى دوتروه مداخله و كنترل در طول مدت فاز فاز فعال زايمان 
محمدى راد (ع) در مطالعه خود تأثير شربت زعفران با يا

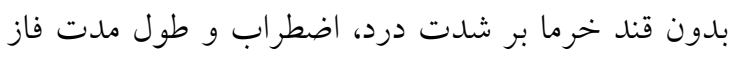

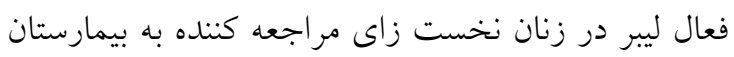

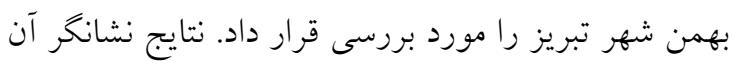

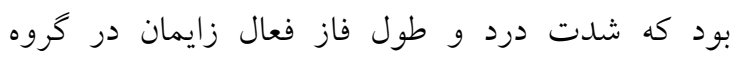
مصرف شربت زعفران به همراه قند خرما در مقايسه با بان

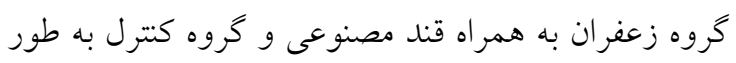

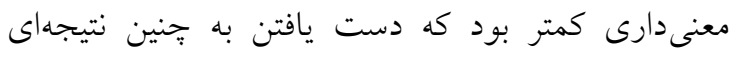

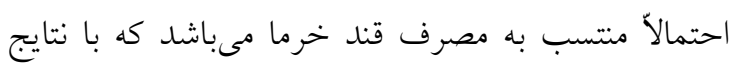

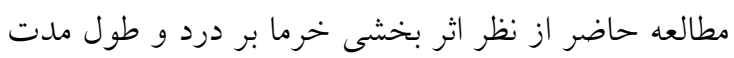
زايمان همخوانى دارد. رحمانى و همكاران(Yع) بر مبناى اين فرضيه كه دريافت دارد

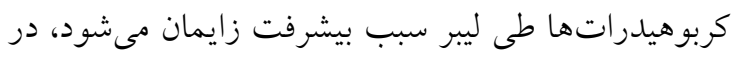

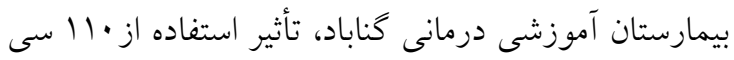

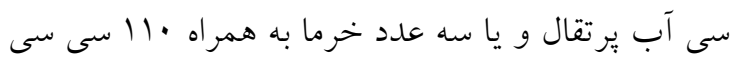

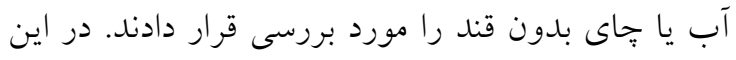

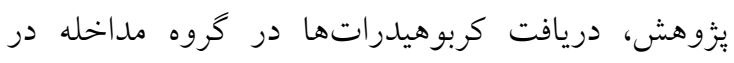

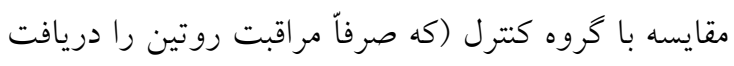

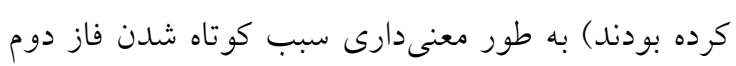

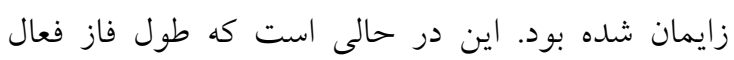
زايمان در دو گروه مداخله و كتترل تفاوت آمارى معنى ندان دارى نداشت. در اين يزوهش دريافت كربوهيدرات مد مد مداته

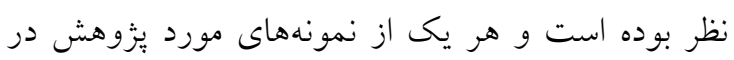

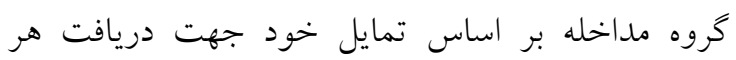

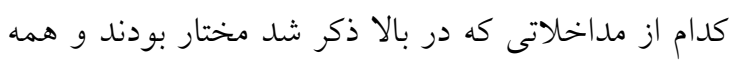
ى نمونهها از يكى نوع ماده غذايى استفاده نكرده بودند.

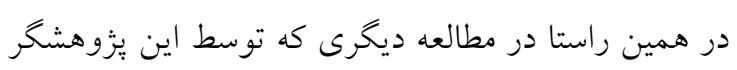

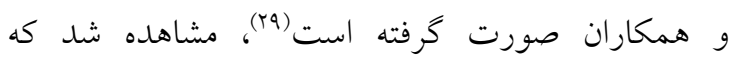

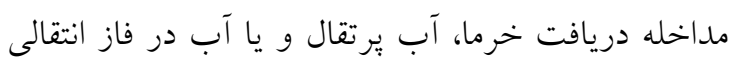
زايمان سبب كاهش ميزان درد و اضطراب شده است. لازم به ذكر است در مطالعه مذكور هدف يزوهشيكر

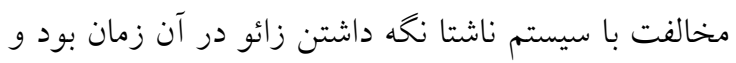

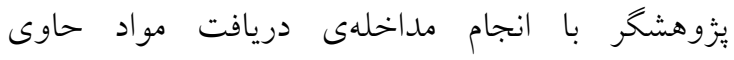

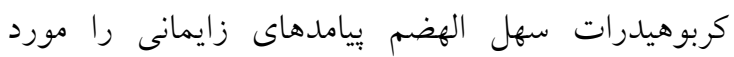

\section{بحث و نتيجه تيرى} نتايج يزوهش حاضر حاكى از اثربخشى خرى خرما بر كاهش

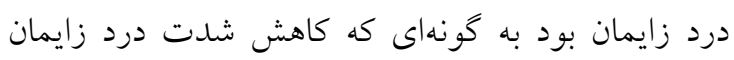

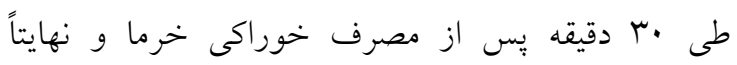
كاهش طول مدت فاز فعال زايمان بود. در ارتباط با تبيين

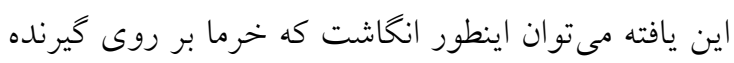

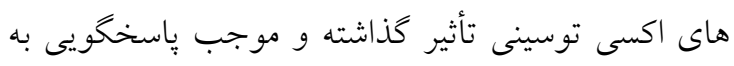

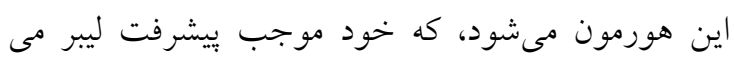

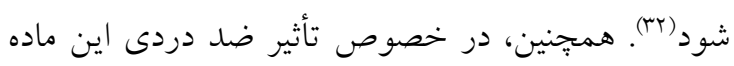

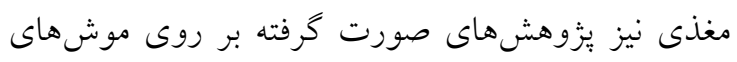

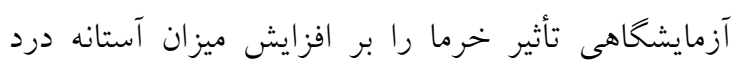

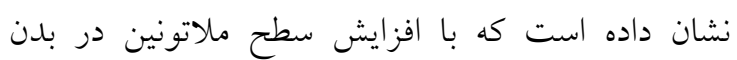
موشهاى آزمايشخاهى همر اه بوده است (rr).

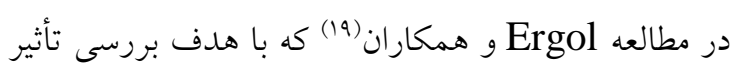

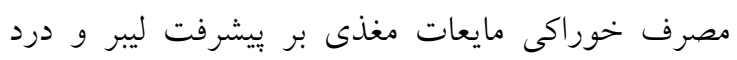
زايمان در بيمارستان آموزشى آنكارا انجام شد، طول فئن فاز

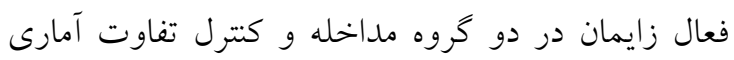
معنى دارى نشان نداد و مصرف مايعات مغذى طى دي لبير

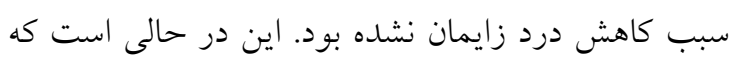

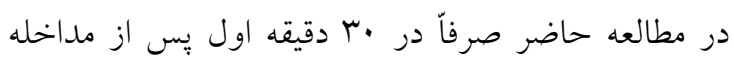

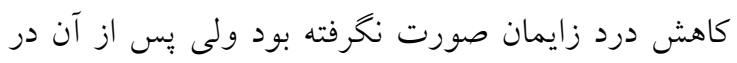
دقايق •10-7.7 شدت درد ليبر و همجنين طول فاز فعال زايمان به طور معنى دارى در گروه مداخله كاهش يافته

كردى و همكاران(TV) در بزوهش خود كه در بيمارستان

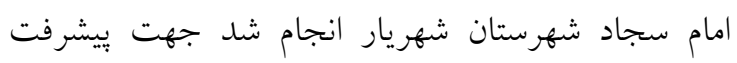
زايمان از شربت عسل خرما استفاده كرده بودند. نتايج

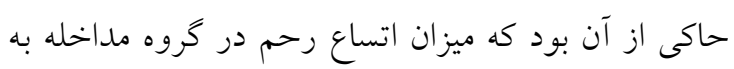

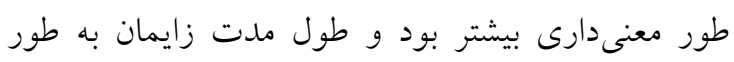
معنىدارى كاهش يافته بود. در مطالعه ما نيز طول فاز

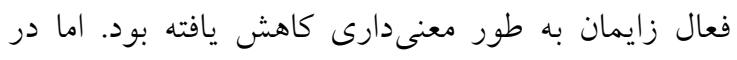

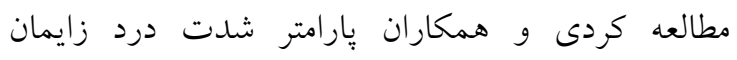

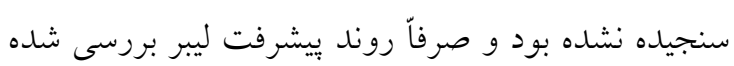




$$
\begin{aligned}
& \text { اثرات ضد دردى نيز دارد، جهت تأمين انرزى زائو و } \\
& \text { تجديد قواى جسمانى و كاهش درد زايمان در ليبر }
\end{aligned}
$$

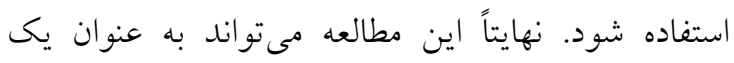

$$
\begin{aligned}
& \text { يزوهش بايه براى مطالعات بعدى مورد استفاده قرار كيرد. }
\end{aligned}
$$

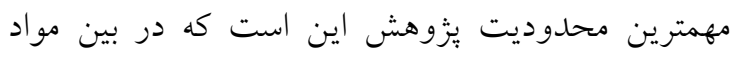

$$
\begin{aligned}
& \text { غذايى كداميك اثربخشى بيشترى دارد كه در هالهاى از } \\
& \text { ابهام قرار دارد و اين امر نيازمند مداخلات مقايسهاى بين }
\end{aligned}
$$

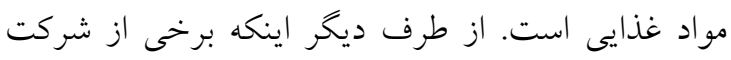

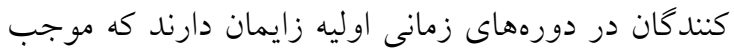

$$
\begin{aligned}
& \text { ريزش نمونه مىشود كه نيازمند اين است كه در ابتداى ردماي } \\
& \text { امر نمونه با حجم بيشترى انتخاب شود. }
\end{aligned}
$$$$
\text { تعارض منافع: هيج كونه تعارض منافع از سوى }
$$$$
\text { نويسندكان بيان نشده است. }
$$

\section{تقدير و تشكر}

از تمامى كاركنان بيمارستان آموزشى درمانى خيريه عسلى لم

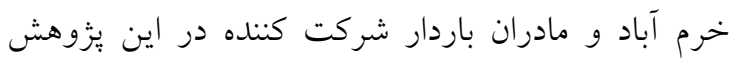

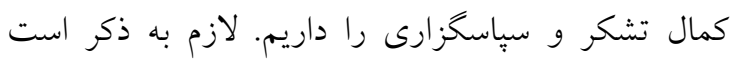

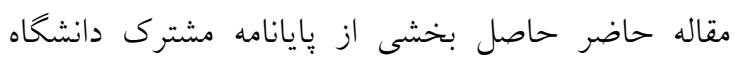

$$
\text { علوم بزشكى ايران و تهران بوده است. }
$$

$$
\begin{aligned}
& \text { سنجش قرار داده است. در اين مطالعه مشخص نشد كه }
\end{aligned}
$$

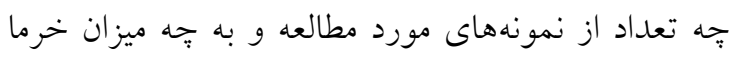

$$
\begin{aligned}
& \text { مصرف كردهاند و جنين نتيجه گيرى كردهاندكه به طور }
\end{aligned}
$$

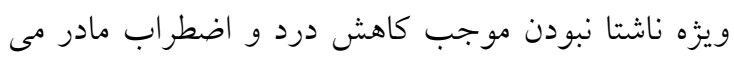

$$
\begin{aligned}
& \text { كردد. اين در حالى است كه مبناى يزوهش ما بـ به طورد }
\end{aligned}
$$

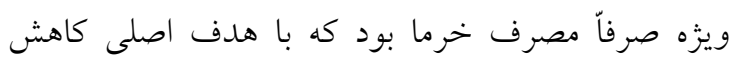

$$
\begin{aligned}
& \text { درد زايمان مورد يزوهش قرار كرفت و و متعاقبًا روند } \\
& \text { بيشرفت ليبر مورد ارزيابى قرار كرفت و بر خلاف } \\
& \text { يُزوهش رحمانى طول فاز فعال زايمان در يُزوهش ما به } \\
& \text { طور معنى دارى كاهش يافته بود كه ممكن است دليل اين } \\
& \text { تفاوت را در اين دانست كه تمام نمونههاى كروه مداخله } \\
& \text { در يُزوهش ما خرما دريافت كردند و در مقايسه با مطالعه } \\
& \text { رحمانى مقدار خرماى دريافتى نيز بيشتر بود. }
\end{aligned}
$$

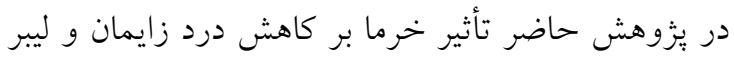

$$
\begin{aligned}
& \text { كاملاً مشهود بود. نكته مهم و قابل توجه اين بود كه خرما } \\
& \text { با وجود كاهش شدت درد زايمان، موجب طولانى شدن }
\end{aligned}
$$

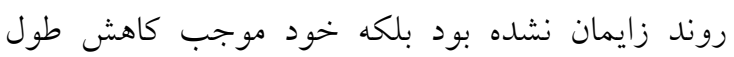

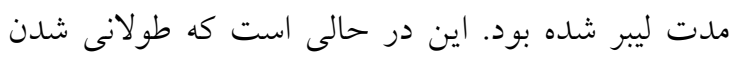

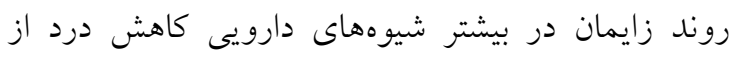

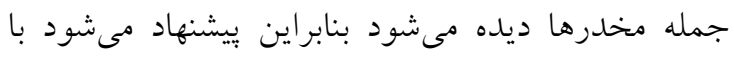

$$
\begin{aligned}
& \text { توجه به اينكه نداشتن محدوديت در خوردن و وآشاميدن }
\end{aligned}
$$

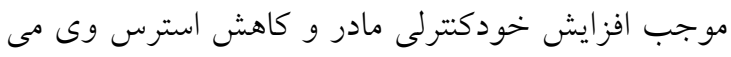

$$
\begin{aligned}
& \text { شود، از خرما كه مادهاى مغذى و بلدون عارضه بوده و }
\end{aligned}
$$

\section{References}

1. Treede R-D. The International Association for the Study of Pain definition of pain: as valid in 2018 as in 1979, but in need of regularly updated footnotes. Pain reports. 2018;3(2).

2. Avery MD. Supporting a physiologic approach to pregnancy and birth: A practical guide: John Wiley \& Sons; 2013.

3. Fishman SM. Bonica's management of pain: Lippincott Williams \& Wilkins; 2012.

4. Nanbakhsh F, Ahmadnejad E, Jalili N, Zadeh Mohammadi A. the Effect of Music in Reducing the Pain and Stress during Delivery. J Urmia Univ Med Sci. 2009;20(3):209-14. [Persian].

5. Reynolds F. Regional analgesia in obstetrics: a millennium update: Springer; 2000.

6. Neal JL, Ryan SL, Lowe NK, Schorn MN, Buxton M, Holley SL, et al. Labor dystocia: uses of related nomenclature. J Midwifery Womens Health. 2015;60(5):485-98.

7. Yelikar K, Deshpande S, Deshpande R, Lone D. Safety and efficacy of oral mifepristone in preinduction cervical ripening and induction of labour in prolonged pregnancy. J Obstet Gynecol India. 2015;65(4):221-5.

8. Harrison MS, Ali S, Pasha O, Saleem S, Althabe F, Berrueta M, et al. A prospective populationbased study of maternal, fetal, and neonatal outcomes in the setting of prolonged labor, 
obstructed labor and failure to progress in low-and middle-income countries. Reproductive health. 2015;12(2):S9.

9. SAAT SS, HAJI AM, Basirat Z, NAZARI R, Beheshti Z. Comparison of atropine-promethazine combination and pethidine effects on active phase of labor. Journal of Babol University of Medical Sciences. 2007;3(9):39-42. [Persian].

10. Huntley AL, Coon JT, Ernst E. Complementary and alternative medicine for labor pain: a systematic review. Am J Obstet Gynecol. 2004;191(1):36-44.

11. Eisenach JC, Pan PH, Smiley R, Lavand'homme P, Landau R, Houle TT. Severity of acute pain after childbirth, but not type of delivery, predicts persistent pain and postpartum depression. Pain. 2008;140(1):87-94.

12. Chaillet N, Belaid L, Crochetière C, Roy L, Gagné GP, Moutquin JM, et al. Nonpharmacologic approaches for pain management during labor compared with usual care: a meta-analysis. Birth. 2014;41(2):122-37.

13. Sharma S, Menia V, Bedi J, Dogra S. Labor analgesia: An unmet right of laboring women in India. J South Asian Fed Obstet Gynaecol. 2013;5:26-32.

14. Cunningham FG, MacDonald PC, Gant NF. Williams obstetrics: McGraw-Hill Professional New York, NY; 2005.

15. Smith CA, Levett KM, Collins CT, Armour M, Dahlen HG, Suganuma M. Relaxation techniques for pain management in labour. Cochrane Database of Systematic Reviews. 2018 (3).

16. Behmanesh F, Pasha H, Zeinalzadeh M. The effect of heat therapy on labor pain severity and delivery outcome in parturient women. Iranian Red Crescent Medical Journal. 2009;11(2):18892. [Persian]

17. Behmanesh F, Fahami F, Zeynalzadeh M, Bizhani A. Effect of heat therapy on pain severity and duration of labor in primigravida women. 2008. [Persian]

18. imkin P, Klein MC. Nonpharmacological approaches to management of labor pain. UpToDate online. 2007;15.

19. Ergol S, Eroglu K, Taskin L. The effect of oral fluid food support during labor on labor duration and perception of labor pains. HealthMED. 2012;6(6):2093-9.

20. American of Nurse-Midwives AC. Providing Oral Nutrition to Women in Labor. Journal of Midwifery \& Women's Health. 2008;53(3):276-83..

21. 21. Shea-Lewis A, Eckardt P, Stapleton D. CE: Original Research An Investigation into the Safety of Oral Intake During Labor. AJN The American Journal of Nursing. 2018;118(3):24-31.

22. Hosseini E, Asadi N, Zareei F. Effect of massage therapy on labor progress and plasma levels of cortisol in the active stage of first labor. Zahedan Journal of Research in Medical Sciences. 2013;15(9):35-8. [Persian]

23. Carvalho B, Zheng M, Aiono-Le Tagaloa L. A prospective observational study evaluating the ability of prelabor psychological tests to predict labor pain, epidural analgesic consumption, and maternal satisfaction. Anesth Analg. 2014;119(3):632-40.

24. Rahmani R, Khakbazan Z, Yavari P, Granmayeh M, Yavari L. Effect of oral carbohydrate intake on labor progress: randomized controlled trial. Iranian journal of public health. 2012;41(11):59. [Persian]

25. Ahmad M, Khan MA, Marwat SK, Zafar M, Khan MA, Hassan TU, et al. Useful medicinal flora enlisted in Holy Quran and Ahadith. Am Eurasian J Agric Environ Sci. 2009;5(1):126-40.

26. Mojahed S, Aflatunian A, Khadem N, Dehghani Firouzabadi R, Karimi Zarchi M. An investigation into effectiveness of date (Rutab) on postpartum hemorrhage. SSU_Journals. 2012;20(2):159-66. [Persian]

27. Kordi M, Nasiri N, Safarian M, Esmaili H, Shadjuo K. The effect of oral honey-date syrup intake during labor on labor progress of nulliparous women. Iranian Journal of Obstetrics, Gynecology and Infertility. 2010;13(2):23-30. [Persian]

28. Kordi M, Aghaei Meybodi F, Tara F, Nemati M, Taghi Shakeri M. The effect of late pregnancy consumption of date fruit on cervical ripening in nulliparous women. Journal of Midwifery and Reproductive Health. 2014;2(3):150-6. [Persian]

29. Rahmani BR, Khakbazan Z, Bahri N, Baloochi T, Khargani R. The effect of food intake during labor on pain and anxiety in pregnant women. Zahedan Journal of Research in Medical Sciences. 2012;13(8):44-7. [Persian] 
30. Winkelman C, Norman D, Maloni JA, Kless JR. Pain measurement during labor: comparing the visual analog scale with dermatome assessment. Appl Nurs Res. 2008;21(2):104-9.

31. Al-Kuran O, Al-Mehaisen L, Bawadi H, Beitawi S, Amarin Z. The effect of late pregnancy consumption of date fruit on labour and delivery. J Obstet Gynaecol. 2011;31(1):29-31.

32. Ahmed IE, Mirghani HO, Mesaik MA, Ibrahim YM, Amin TQ. Effects of date fruit consumption on labour and vaginal delivery in Tabuk, KSA. Journal of Taibah University Medical Sciences. 2018;13(6):557-63.

33. Shabani M, Zangiabadi N, Asadi-Shekaari M. Evidence for positive effects of date extract that attenuates thermal hyperalgesia in a diabetic rat model of neuropathic pain. Neurosci Med. 2013;4(01):16.

34. Mohammadierad R, Mohammad-Alizadeh-Charandabi S, Mirghafourvand M, Fazil F. Effect of Saffron with or Without Date Sugar on Intensity of Pain and Anxiety During Labor in Primiparous Females: A Randomized, Controlled Trial. Iranian Red Crescent Medical Journal. 2018;20(S1). [Persian] 